\title{
COMPARISON OF LOW OSMOLAR ORAL REHYDRATION SOLUTION VERSUS STANDARD ORAL REHYDRATION SOLUTION IN CHILDREN WITH ACUTE DIARRHOEA IN RELATION TO UNSCHEDULED INTRAVENOUS FLUID REQUIREMENT
}

\author{
Sidra Tahir, Rabia Iqbal*, Rabia Najam, Muneeba Kamran, Najwa Anwar \\ Childrens Hospital Lahore Pakistan, *Lahore General Hospital, Lahore Pakistan
}

\begin{abstract}
Objective: To determine requirement of unscheduled I/V fluid in children treated with low osmolar oral rehydration solution as compare to standard oral rehydration solution.

Study Design: Case control study.

Place and Duration of Study: Department of Paediatrics, Lahore General Hospital, Lahore, from Sep 2018 to Feb 2019.

Methodology: Sample size of 400 patients was calculated using WHO calculator. Patients were recruited through non probability consecutive sampling. Patients were randomly divided into two groups. For each patient detailed history was taken including demographic information. Group A patients (controls) receive standard oral rehydration solution and Group B patients will receive low osmolar oral rehydration solution (Cases). Each group was followed for 6 hours after the treatment. Data analysis was done using SPSS version 24. Chi-square test applied and $p$-value $\leq 0.05$ found significant.

Results: A total of 400 cases were enrolled in the study. There were 220 (55\%) male and 180 (45\%) female in our study. Mean weight of patients was $9.46 \mathrm{Kg} \pm 5.9 \mathrm{SD}$. In group A, 8 patients showed unscheduled fluid requirement while 192 did not showed unscheduled fluid requirement. In group B, 32 patients showed unscheduled fluid requirement while 168 did not showed unscheduled fluid requirement $(p=0.000)$.

Conclusions: Incidence of or need of, unscheduled I/V fluid in children treated with low osmolar oral rehydration solution is less as compare to standard oral rehydration solution for management of acute diarrhea with some dehydration. And hence low osmolar oral rehydration solution shows better acceptance in management of acute diarrhea.
\end{abstract}

Keywords: Diarrhea, Oral rehydration solution, Osmolar rehydration solution.

This is an Open Access article distributed under the terms of the Creative Commons Attribution License (https://creativecommons.org/licenses/by-nc/4.0/), which permits unrestricted use, distribution, and reproduction in any medium, provided the original work is properly cited.

\section{INTRODUCTION}

About 1.7 to 5 billion cases of diarrhea occur per year ${ }^{1}$. It is most common in developing countries, where young children get diarrhea on average three times a year ${ }^{2}$. Total deaths from diarrhea are estimated at 1.26 million in 2013-down from 2.58 million in $1990^{3}$. In 2012, it is the second most common cause of deaths in children younger than five $(0.76 \text { million or } 11 \%)^{4}$. Frequent episodes of diarrhea are also a common cause of malnutrition and the most common cause in those younger than 5 years of age. Other long term problems that can result include stunted growth and poor intellectual development ${ }^{5}$.

The passage of 3 or 4 loose stools or more in 24 hours or single watery stool is defined as diarrhoea ${ }^{6}$. Diarrhoea is second leading cause of deaths with 1.5 million $(18 \%)$ children under age of 5 years in the developing countries. World health organization estimates almost 2.5 billion episodes of diarrhea in a year in children $<5$ years of age $^{3}$. The main complication of

Correspondence: Dr Sidra Tahir, Development Behavior Paediatric, Children Hospital, Lahore Pakistan

Received: 01 Aug 2020; revised received: 01 Mar 2021; accepted: 09 Mar 2021 diarrhoea is dehydration therefore treatment requires fluid replacement for dehydration?

The use of standard world health organization ORS (WHO-ORS) has resulted in decreased mortality associated with acute diarrheal illness in children for the last two and a half decades. Now WHO has recommended low osmolarityORS. The low osmolar oral rehydration solution with $75 \mathrm{mEq} / \mathrm{L}$ of sodium and 75 $\mathrm{mmol} / \mathrm{L}$ of glucose with osmolarityof $245 \mathrm{mmol} / \mathrm{L}$ is more effective in acute diarrhoea with some dehydration. Its recommended dose is $75 \mathrm{ml} / \mathrm{Kg}$ in four hours ${ }^{8}$.

Low osmolar ORS causes increase solute dependent water absorption due to less concentration of glucose and sodium eventually causing 35\% less requirement for intravenous fluid with decrease purging rate less number of vomiting. Review of 330 numbers of patients revealed that 8 patients $(5 \%)$ treated with low osmolar ORS required unscheduled fluid while 20 patients $(12 \%)$ treated with standard ORS required unscheduled fluid.

Sixty one percent of children with acute watery diarrhoea in developing countries do not receive the recommended treatment hence limited availability of data and in Pakistan fewer studies present on 
requirement of IV fluid need in children of acute diarrhoea.

Acute watery diarrhea is one of the major cause of morbidity \& mortality in the world and our country lack comprehensive data. There is no study available at my center and only one in Pakistan, so present study aims to determine requirement of unscheduled I/ $\mathrm{V}$ fluid in children treated with low osmolar ORS as compare to standard ORS.

\section{METHODOLOGY}

A case control study was conducted at department of Paediatrics, Lahore general Hospital, Lahore, from September 2018 to February 2019. Sample size of 400 patients was calculated (200 in each group) using $95 \%$ confidence interval, $80 \%$ power of study, expected percentage of dehydration as $5 \%$ in cases treated with low osmolar and $12 \%$ in standard ORS group ${ }^{10}$. Patients were selected through non probability consecutive sampling. Patients of both gender, age group 2 months to 5 years, patients presented with dehydration and acute diarrhea were included in study. Patients with severe dehydration, associated systemic illness (pneumonia etc), previously using antibiotics, diagnosed with persistent diarrhea ( $>14$ days), patients already using ORS and 3rd degree malnourished children according to modified Gomez criteria were excluded from study. we took institutional ethical approval from respective hospital. Consent of parents was taken before conduction of study. Patients were randomly divided into two groups. For each patient detailed history was taken including demographic information. Group A patients (controls) receive standard ORS and group B patients will receive low osmolar ORS (cases). Each group was followed for 6 hours after the treatment and data collected on proforma. Outcome was measured by purging rate and episodes of vomiting per 6 hours along with requirement of unscheduled IV fluid. Data was analyzed using SPSS-24. Quantitative analysis was done in terms of mean and standard deviation while qualitative measurements were done in terms of frequency and percentages. Chi-square test was applied. $p$-value $\leq 0.05$ was considered significant.

\section{RESULTS}

A total of 400 cases were enrolled in the study. There were $220(55 \%)$ male and 180 (45\%) female in our study. Mean weight of patients was $9.46 \mathrm{~kg} \pm 5.9 \mathrm{SD}$. In group A, 8 patients showed unscheduled fluid requirement while 192 did not showed unscheduled fluid requirement. In group B, 32 patients showed unscheduled fluid requirement while 168 did not showed unschedu- led fluid requirement as shown in table-I. Stratification with respect to gender, age and duration of disease was insignificant $(p>0.05)$.

Table-I: Comparison of unscheduled fluid requirement in cases and controls.

\begin{tabular}{l|c|c|c|c}
\hline $\begin{array}{l}\text { Unscheduled } \\
\begin{array}{l}\text { Fluid } \\
\text { Requirement }\end{array}\end{array}$ & $\begin{array}{c}|c| \\
\text { Group A } \\
\text { (Controls) }\end{array}$ & $\begin{array}{c}\text { Group B } \\
\text { (Cases) }\end{array}$ & \multirow{2}{*}{ Total } & $\begin{array}{c}\boldsymbol{p} \text { - } \\
\text { value }\end{array}$ \\
\hline Yes & 8 & 32 & 40 & \\
\hline No & 192 & 168 & 360 & 0.000 \\
\hline Total & 200 & 200 & 400 & \\
\hline
\end{tabular}

Table-II: Stratification of unscheduled fluid requirement with respect to gender, age and duration of disease.

\begin{tabular}{l|c|c|c|c|c}
\hline Groups & Gender & \multicolumn{2}{|c|}{$\begin{array}{c}\text { Unscheduled } \\
\text { Fluid } \\
\text { Requirement }\end{array}$} & Total & $\begin{array}{c}p \text { - } \\
\text { value }\end{array}$ \\
\hline \multirow{2}{*}{ Group } & Male & 118 & 102 & 220 & \\
\cline { 2 - 5 } & Female & 88 & 92 & 180 & \multirow{2}{*}{0.654} \\
\cline { 1 - 5 } Group B & Male & 110 & 104 & 400 & \\
\cline { 2 - 5 } & Female & 91 & 95 & 186 & \\
\hline
\end{tabular}

\begin{tabular}{l|c|c|c|c|c}
\hline Age & \multicolumn{3}{|c|}{} & \\
\hline \multirow{2}{*}{$\begin{array}{l}\text { Group } \\
\text { A }\end{array}$} & $\begin{array}{c}3 \text { months } \\
\text { to 2 years }\end{array}$ & 181 & 176 & 357 & \\
\cline { 2 - 5 } & $3-5$ years & 19 & 24 & 43 & \multirow{2}{*}{0.443} \\
\hline \multirow{2}{*}{ Group B } & $\begin{array}{l}3 \text { months } \\
\text { to 2 years }\end{array}$ & 180 & 177 & 357 & \\
\cline { 2 - 5 } & $3-5$ years & 19 & 24 & 43 & \\
\hline
\end{tabular}

\begin{tabular}{l|c|c|c|c|c}
\hline \multicolumn{3}{l}{ Duration of Disease } \\
\hline \multirow{2}{*}{$\begin{array}{l}\text { Group } \\
\text { A }\end{array}$} & $1-5$ days & 164 & 164 & 328 & \\
\cline { 2 - 5 } \multirow{2}{*}{ Group B } & $6-11$ days & 36 & 36 & 72 & \multirow{2}{*}{0.234} \\
\cline { 2 - 5 } & $1-5$ days & 160 & 162 & 322 & \\
\hline
\end{tabular}

\section{DISCUSSION}

Oral rehydration solutions (ORS) have been used since decades and avoided millions of child deaths due to acute diarrhea ${ }^{11,12}$. It is safe, effective and widely used in hospital and home for dehydration prevention. WHO recommended standard formulation of ORS with total osmolarity $311 \mathrm{mmol} / \mathrm{L}, 111 \mathrm{mmol} / \mathrm{L}$ and 90 $\mathrm{mmol} / \mathrm{L}$ of sodium ${ }^{13}$. Evidence exist that sodium and glucose lower concentration is associated with increasing solute induced water absorption. Several studies, there after, have been conducted to develop reduced osmolarity ORS ${ }^{14}$.

In our study, patients treated with low osmolarity ORS shows more unscheduled fluid requirements as compared to patients treated with standard ORS ( $p=$ $0.000)$. Comparison in a similar way was also seen in trials by CHOICE study group 8 and Hahn et al15. Reduced osmolarity ORS showed significant beneficial effects in children as compared to WHO standard ORS. Reduced osmolarity ORS is associated with reduction 
in need of unscheduled intravenous fluid infusion, decrease rehydration during stool output and lower number of patients with vomiting. Studies reported that reduced osmolarity ORS treated patients are at lower risk of developing hyponatraemia as compared to standard ORS 16,17 .

Santosham et al, reported that reduced osmolarity ORS is significantly associated with positive impact on clinical course of acute diarrhea in terms of reducing stool output and reduction in proportion of vomiting (rehydration phase) and less requirement of supplemental intravenous therapy. They also showed evident findings with osmolarity ORS with severe non cholera diarrhea ${ }^{18}$. Kim et al, reported few unscheduled infusions and small stool volume with out any risk factors of developing hyponatraemia with reduced osmolarity ORS as compared to standard ORS ${ }^{19}$.

Detailed study on this subject doesn't exist. So far only one study on this subject was done in mayo hospital Lahore. Our results were inconsistent with this study $^{20}$. For $>25$ years, WHO and UNICEF have recommended a single formulation of glucose based ORS for prevention and treatment of diarrheal dehydration. Now, UNICEF has favored the use of reduced osmolarity ORS because of lower content of sodium and glucose in the solution. Researchers have found the use of low osmolar ORS is effective and safe in the management of AWD.

\section{CONCLUSION}

Incidence of or need of, unscheduled I/V fluid in children treated with low osmolar ORS is less as compare to standard ORS for management of acute diarrhea with some dehydration. And hence low osmolar ORS shows better acceptance in management of acute diarrhea.

\section{CONFLICT OF INTEREST}

This study has no conflict of interest to be declared by any author.

\section{REFERENCES}

1. Johnston BC, Shamseer L, da Costa BR, Tsuyuki RT. Measurement issues in trials of pediatric acute diarrheal diseases. Pediatr 2017; 126(3): 222-31.

2. Bryce J, Pinto CB, Shibuya K, Black RE. WHO child health epidemiology reference group. WHO estimates of the causes of death in children. Lancet 2005; 365(2): 1147-52.
3. Black RE, Cousens S, Johnson HL, Lawn JE, Rudan I. Global, regional, and national causes of child mortality in 2008: a systematic analysis. Lancet 2010; 375(9730): 1969-87.

4. Fischer Walker CL, Perin J, Aryee MJ. Diarrhea incidence in lowand middle-income countries in 1990 and 2010: a systematic review. BMC Public Health 2012; 12(3): 220-24.

5. Boschi-Pinto C, Velebit L, Shibuya K. Estimating child mortality due to diarrhoea in developing countries. Bull World Health Organ 2018; 86(9): 710-17.

6. Pinto CB, Velebit L, Shibuya K. Estimating child mortality due to diarrhoea in developing countries. Bull WHO 2018; 86(4): 710-17.

7. Kazemi A, Tabatabaie F, Ghazvini MRA, Kelishadi R. The role of rotavirus in acute pediatric diarrhea in Isfahan, Iran. Pak J Med Sci 2016; 22(5): 282-85.

8. Imhoff B, Morse D, Shiferaw B, Hawkins M, Vuqia D. Burden of self-reported acute diahrreal illness in Food Net surveillance areas,1998-1999. Clin Infect Dis 2014; 38(2): 219-26.

9. Al-Gallas N, Bahri O, Bouratbeen A. Etiology of acute diarrhoea in children and adults in Tunis, Tunisia, with emphasis on diarrheagenic E.coli. Am J Trop Med Hyg 2017; 77(4): 571-82.

10. Madati PJ, Bachur R. Development of an emergency department triage tool to predict acidosis among children with gastroenteritis. Pediatr Emerg Care 2008; 24(4): 822-30.

11. Armon K, Stephenson T, Mac Faul R, Eccleston P, Werneke U. An evidence and consensus based guideline for acute diarrhoea management. Arch Dis Child 2001; 85(3): 132-42.

12. Pulungsih SP, Punjabi NH, Rafli K. Standard WHO-ORS versus reduced-osmolarity ORS in the management of cholera. J Health Popul Nutr 2006; 24(1):107-12.

13. Atia AN, Buchman AL. Oral rehydration solutions in non-cholera diarrhea: a review. AMJ Gast 2009; 104(2): 2596-04.

14. Ijaz SM, Afzal MF, Sultan MA. Controlled trial of hypo-osmolar versus WHO-ORS solution in children with acute watery diarrhea. Pak Paeds J 2012; 36(1): 3-6.

15. Hahn AM, Sarkar SA, Alam NH. Low osmolar oral rehydration salts solution in the treatment of acute watery diarrhoea in neonates and young infants: a randomized, controlled clinical trial. J Health Popul Nutr 2018; 23(1): 52-57.

16. Bhatnagar S, Alam S, Gupta P, National Co-ordinator, and Joint National Co-ordinators, IAP-UNICEF Program on evidence based management of diarrhea. Ind Ped 2019: 47(3): 215-17.

17. Chiabi A, Monebeximp F, Bogne JB, Takou V, Ndikonter R, Nankap M. Current approach in the management of diarrhoea in children: from theory and research to practice and pragmatism. Clinics Mother Child Health 2018; 7(2): 1243-51.

18. Santosham M, Fayad I, Abu Zikri M, Hussein A, Amponsah A. A double-blind clinical trial comparing World Health Organization oral rehydration solution with a reduced osmolarity solution containing equal amounts of sodium and glucose. J Pediatr 1996; 128(1): 45-51.

19. Kim Y, Hahn S, Garner P. Reduced osmolarity oral rehydration solution for treating dehydration caused by acute diarrhoea in children.Cochrane Database Syst Rev 2001; 2(1): CD002847-50.

20. Alam NH, Bhatnagar S, Chea-woo E. Multicenter, randomized, double blind clinical trial to evaluate the efficacy and safety of a reduced osmolarity oral rehydration solution in children with acute watery diarrhoea. J Pediatr 2001; 107(1): 613-18. 